\title{
Effect of cytochalasin A on apical growth, actin cytoskeleton organization and enzyme secretion in Aspergillus nidulans
}

\author{
Sara Torralba, ${ }^{1}$ Marjatta Raudaskoski, ${ }^{2}$ Ana María Pedregosa ${ }^{1}$ \\ and Fernando Laborda'
}

Author for correspondence: Sara Torralba. Fax: +34 1 8854621.e-mail: mpampp@microb.alcala.es

\footnotetext{
1 Departament de Microbiología y

Parasitología, Universidad de Alcalá de Henares,

Carretera Madrid-

Barcelona, Km 33, E-28871

Alcalá de Henares, Madrid, Spain

2 Division of Plant Physiology, Department of Biosciences, University of Helsinki, PO Box 56,

Viikinkaari 9, FIN-00014, University of Helsinki,

Finland
}

\begin{abstract}
The role of actin in apical growth and enzyme secretion in the filamentous fungus Aspergillus nidulans was studied by treating the hyphae with cytochalasin A (CA), which inhibits actin polymerization. Indirect immunofluorescence microscopy revealed actin at the tips of main hyphae and branches, and at the sites of developing septa. CA inhibited the growth of the fungus and changed the growth pattern of hyphal tips from cylindrical tubes to spherical beads. The regions with swellings showed no actin fluorescence, and neither was actin seen in association with septa. After $4 \mathrm{~h}$ exposure, hyphae were able to resume the normal tip growth pattern in the presence of CA for a short period of time and new cylindrical hyphae, with actin fluorescence at the apex, emerged from the swollen tips. Later, the tips of the hyphae swelled again, which led to a beaded apperance. We also studied the effect of CA on the secretion of $\alpha$ - and $\beta$-galactosidase. $\alpha$-Galactosidase is secreted into the culture medium, whereas $\beta$-galactosidase remains in the mycelium, with part of its activity bound to the cell wall. When A. nidulans mycelium was incubated in the presence of $C A$, a reduction in the secretion of $\alpha$-galactosidase into the culture medium and a decrease in the $\alpha$ - and $\beta$ galactosidase activities bound to the cell wall was detected. However, the CA dose used for the hyphae did not modify the secretion of the enzymes from protoplasts. Results described here provide evidence that a polymerized actin cytoskeleton is required for normal apical growth, hyphal tip shape and polarized enzyme secretion in A. nidulans. Cytochalasin-induced disruptions of the actin cytoskeleton could result in the alterations of apical growth and inhibition of enzyme secretion observed by blocking secretory vesicle transport to the apex.
\end{abstract}

Keywords : actin, cytochalasin, Aspergillus nidulans, $\alpha$-galactosidase, $\beta$-galactosidase

\section{INTRODUCTION}

A characteristic of many filamentous fungi is their ability to secrete large amounts of proteins into the culture medium. Fungal exoenzymes are used in a variety of industries, especially in relation to food (Lowe, 1992). The ability of filamentous fungi to secrete enzymes into the culture medium has also made them attractive candidates as hosts for heterologous protein production,

Abbreviations: CA, cytochalasin A; DAPI, diamidinophenylindole; IIF, indirect immunofluorescence. since enzyme secretion facilitates purification (Archer \& Wood, 1994).

Our understanding of the molecular mechanisms regulating protein secretion in filamentous fungi is still very limited, but it has been proposed that the major stages and compartments of the secretion process in filamentous fungi are probably similar to those identified in budding yeast and other eukaryotic cells (Sheckman $\&$ Novick, 1982; Pryer et al., 1992). Indications for this come from analysis of the hyphal ultrastructure of various fungi grown under conditions that promote efficient protein secretion (Punt et al., 1994). Most of the 
extracellular fungal enzymes are glycoproteins. In budding yeast, following synthesis in the rough endoplasmic reticulum, where the initial steps of glycosylation occur, proteins are transported to the Golgi apparatus, where further glycosylation takes place (Tanner \& Lehle, 1987). Proteins are packaged within vesicles that are transported to the cell surface, where they fuse with the plasma membrane, liberating their contents to the periplasmic space. Proteins may then remain within the periplasmic space, be retained at the mature cell wall, or pass through the cell wall into the medium (Farkas, 1979; Gooday, 1994).

Protein secretion is related to fungal growth. Yeast mutants specifically blocked in secretion are defective in cell-surface expansion (Novick \& Sheckman, 1983). In filamentous fungi, growth and protein secretion are polarized processes mainly restricted to the growing hyphal tips (Wösten et al., 1991), where the cell wall is more porous than in the mature wall, perhaps allowing the rapid diffusion of proteins (Chang \& Trevithick, 1974; Wessels, 1993). Little is known about the mechanism involved in polarized vesicle movement to the hyphal tip, although several studies implicate cytoskeletal components in the process (Howard \& Aist, 1980). In hyphae, predominant components of the cytoskeleton are microtubules and actin (Salo et al., 1989; Heath, 1990, 1994). A straightforward approach to determine the role of cytoskeleton components on growth and secretion is to disrupt them with specific inhibitors and examine the effects. Benzimidazolederived anti-microtubular drugs, such as benomyl, have been used to study the role of microtubules on growth and protein secretion in filamentous fungi. However, these studies have not led to conclusive results (Howard \& Aist, 1980; Monistrol et al., 1988; Peterbauer et al., 1992; Jochová et al., 1993; Pedregosa et al., 1995; Torralba et al., 1996). Cytochalasins are known for their ability to inhibit polymerization of actin in vivo and can be used to study the functions of the actin cytoskeleton (Srinivasan et al., 1996). Among cytoskeletal components, actin seems to be the most important for apical growth in yeast and in filamentous fungi (Heath, 1990). Actin has been localized in filamentous fungi by immunological and related methods at the sites of wall formation such as at hyphal tips and at sites of septum formation (Runeberg et al., 1986; Butt \& Heath, 1988; Bourett \& Howard, 1991; Raudaskoski et al., 1991; Czymmek et al., 1995; Srinivasan et al., 1996).

In this work we studied the effect of cytochalasin A (CA) on apical growth and enzyme secretion in Aspergillus nidulans. This fungus is a good model for the study of the role of fungal actin since A. nidulans has only a single gene that encodes a $\gamma$-actin (Fidel et al., 1988) and CA has been shown to block septum formation in this fungus (Harris et al., 1994). We studied the effect of CA on the secretion of two hydrolytic enzymes from $A$. nidulans: $\alpha$-galactosidase, which is secreted into the culture medium (Ríos et al., 1993), and $\beta$-galactosidase, which remains in the periplasmic space and bound to the cell wall (Fantes \& Roberts, 1973; Torralba et al., 1996).
The cell wall plays an important role in controlling secretion in filamentous fungi (Peberdy, 1994), which makes it necessary to quantify not only the levels of enzyme released into the culture medium, but also the portion of secreted protein bound to the cell wall. The analysis of secretion was completed with an immunocytochemical study of actin distribution in the hyphae of $A$. nidulans grown in the presence and absence of the drug. The results support the idea that actin plays a role in apical growth and secretion in A. nidulans.

\section{METHODS}

Fungal strains and culture media. Aspergillus nidulans (Eidam) Winter wild-type strain 2.3, kindly provided by Professor J. F. Peberdy (University of Nottingham, UK) was used in this study. Several culture media were used. Stock cultures were maintained on MYG agar $(0.5 \%$ malt extract, $0.25 \%$ yeast extract, $1 \%$ glucose, $2 \%$ agar). The medium used in microscopy studies was MYL $(0.5 \%$ malt extract, $0.25 \%$ yeast extract, $1 \%$ lactose, $2 \%$ agar). Aspergillus liquid minimal medium (AMM) (Pontecorvo et al., 1953), supplemented with glucose or lactose $(1 \%, w / v)$ as the carbon source, was used in the secretion experiments. CA (Sigma) was dissolved in DMSO and diluted to a final stock concentration of $5 \%$ in DMSO. The concentrations of cytochalasin used in this study varied from 1 to $500 \mu \mathrm{g} \mathrm{ml}^{-1}$ and were obtained by dilutions of the stock solution. Solvent concentration in the medium was never more than $0 \cdot 1 \%(\mathrm{v} / \mathrm{v})$. Control experiments with DMSO did not show any detectable alteration as compared to the control without the solvent.

Growth measurements. The growth of $A$. nidulans in the presence of different concentrations of CA $(10,20,50,80$ and $100 \mu \mathrm{g} \mathrm{ml}^{-1}$ ) was studied in both solid and liquid media. The effect of CA on mycelial growth was first tested in solid medium by inoculating MYL agar, with or without the drug, with small agar plugs taken from the edge of actively growing mycelial colonies of $A$. nidulans. Cultures were grown at $28^{\circ} \mathrm{C}$ for $72 \mathrm{~h}$. The diameters of the colonies were measured periodically and the growth at the different times of incubation was expressed as the mean diameter of ten colonies. Fungal growth of $A$. nidulans in liquid medium in the presence of several doses of CA was studied by determination of freezedried weight. Preliminary experiments (data not shown) had indicated that CA prevented germination of conidia from $A$. nidulans. Therefore conidia were allowed to germinate and grow in liquid AMM supplemented with lactose for $48 \mathrm{~h}$ on an orbital shaker at 200 r.p.m. at $28^{\circ} \mathrm{C}$. CA was added to the media and cultures were grown for $72 \mathrm{~h}$ in the absence or presence of different concentrations of the drug. Samples were taken periodically. Mycelia were harvested by filtration through Whatman no.1 paper, washed with distilled water and freeze-dried.

Enzyme activity measurements. Several methods to induce $\alpha$ galactosidase (EC 3.2.1.22) and $\beta$-galactosidase (EC 3.2.1.23) production and secretion in $A$. nidulans were tested. The procedure presented below was finally chosen since it allowed quantification of CA effects on production and secretion of enzymes. Conidia were harvested from MYG agar plates and transferred to liquid AMM supplemented with glucose $(1 \%, \mathrm{w} / \mathrm{v})$ as the carbon source. Cultures were grown on an orbital shaker at 200 r.p.m. at $28^{\circ} \mathrm{C}$ for $48 \mathrm{~h}$ in this medium and then transferred to AMM supplemented with $1 \%$ lactose for $\alpha$ - and $\beta$-galactosidase induction. The cultures were incubated in the lactose medium for $40 \mathrm{~h}$ in the absence 
and presence of $80 \mu \mathrm{g} \mathrm{CA} \mathrm{ml} l^{-1}$. During growth, control and treated cultures were harvested periodically.

To test enzyme production and distribution in A. nidulans hyphae, three fractions were derived from the cultures, according to previously reported methods (Torralba et al., 1996): two fractions were from the mycelium, namely the soluble and insoluble mycelial fractions, and the third fraction was a culture filtrate preparation. The mycelium was separated from the liquid culture by filtration through nylon membranes, washed in $0.5 \mathrm{M}$ Tris/phosphate buffer ( $\mathrm{pH} 6.7$ ), frozen and freeze-dried. The freeze-dried mycelium was weighed to determine its biomass. Cell extracts were obtained by grinding the freeze-dried mycelia in liquid nitrogen to a fine powder with pestle and mortar. The powdered mycelia were resuspended in lysis buffer: $0.5 \mathrm{M}$ Tris/phosphate $\mathrm{pH} 6.7$ containing $10 \%(\mathrm{v} / \mathrm{v})$ glycerol, $0.1 \mathrm{mM}$ dithiothreitol and $2.5 \mathrm{mM}$ PMSF. Cell extracts were centrifuged and the supernatant obtained was used as the soluble mycelial fraction. The pellet was washed three times with lysis buffer, resuspended in the buffer and used as insoluble mycelial fraction (wall fraction) (Vainstein \& Peberdy, 1991). Enzyme activities were determined from all three fractions.

Enzyme distribution was also studied in protoplasts. Protoplasts were prepared in a lytic solution containing $5 \mathrm{mg}$ lysing enzymes $\mathrm{ml}^{-1}$ from Trichoderma harzianum (Sigma) in $0.6 \mathrm{M}$ $\mathrm{KCl}$. After $3 \mathrm{~h}$ gentle agitation at $28^{\circ} \mathrm{C}$ the protoplasts were harvested, washed and transferred into AMM containing $1 \%$ lactose, $0.6 \mathrm{M} \mathrm{KCl}$ and $\mathrm{CA}$ at different concentrations $(0,80$, 100 and $\left.500 \mu \mathrm{g} \mathrm{ml}^{-1}\right)$. The final concentration of cells was adjusted at $10^{8}$ protoplasts $\mathrm{ml}^{-1}$ and protoplasts were incubated at $28^{\circ} \mathrm{C}$ for $50 \mathrm{~h}$. Protoplast growth and regeneration was monitored by phase-contrast microscopy. Enzyme secretion was studied during the first $20 \mathrm{~h}$ incubation, in which the protoplasts did not show tip growth and remained unregenerated. Periodically, protoplasts were separated from culture medium by low-speed centrifugation, washed with $0.6 \mathrm{M} \mathrm{KCl}$ and lysed in distilled water in the presence of $2.5 \mathrm{mM}$ PMSF. $\alpha$-Galactosidase and $\beta$-galactosidase activities were determined in both culture medium and cell lysates. The permeability of the plasma membrane of protoplasts was followed by measuring the activity of the intracellular enzyme malate dehydrogenase activity in protoplasts and in their growth media.

Activities of $\alpha$-galactosidase and $\beta$-galactosidase were assayed by the hydrolysis of a $p$-nitrophenyl-derived substrate into $p$ nitrophenol, which is detected by its absorbance at $420 \mathrm{~nm}$ at basic $\mathrm{pH}$ (Brightwell \& Tappel, 1968). The following substrates were used (at a $2 \mathrm{mM}$ concentration): $p$-nitrophenyl $\alpha$ D-galactopyranoside, dissolved in $0.1 \mathrm{M}$ acetate buffer (pH 4.0), for $\alpha$-D-galactosidase; and $p$-nitrophenyl $\beta$-D-galactopyranoside, dissolved in $50 \mathrm{mM}$ phosphate buffer ( $\mathrm{pH} 7 \cdot 6$ ) plus $2 \mathrm{mM} \mathrm{MgCl}$, for $\beta$-D-galactosidase. The reaction mixture contained $150 \mu \mathrm{l}$ appropriately diluted enzyme solution and $150 \mu \mathrm{l}$ substrate dissolved in buffer. After incubation at $37^{\circ} \mathrm{C}$, the reaction was stopped by addition of $750 \mu l$ Clark \& Lubs (1917) buffer ( $\mathrm{pH} 9 \cdot 8$ ). The material suspended in the insoluble mycelial fractions was removed by centrifugation before spectrophotometric determinations, to avoid interference with the assays. Enzyme units are defined as the amount of enzyme liberating $1 \mu \mathrm{mol} p$-nitrophenol $\mathrm{min}^{-1}$. Total enzyme activity was calculated in units per $\mathrm{mg}$ freeze-dried mycelium or per $10^{8}$ protoplasts. Enzyme activities in the different fractions are expressed as a percentage of the total activity in the cultures. Results are given as the mean of three independent experiments. Two replicate samples were analysed for each determination.
Indirect immunofluorescence (IIF) microscopy. For the visualization of actin and DNA in the hyphae, colonies of $A$. nidulans were grown overnight at $37^{\circ} \mathrm{C}$ on MYL agar medium on small pieces of dialysis membrane covered with $0.5 \%$ (w/v) agarose (Raudaskoski et al., 1991). For exposure of the mycelium to the inhibitor, membranes with small colonies were transferred to MYL plates containing $20 \mu \mathrm{g} \mathrm{CA} \mathrm{ml}^{-1}$ for $6 \mathrm{~h}$. To handle the control and treated colonies similarly, all the control colonies were also transferred to new control plates. The colonies were frozen and freeze-substituted in methanol containing $3.7 \%$ formaldehyde, as described by Raudaskoski et al. (1991). After freeze substitution for $2 \mathrm{~d}$, the samples were gradually rehydrated and prepared for immunolabelling with antiactin N350 monoclonal antibody (Amersham) according to the methods of Raudaskoski et al. (1991). The nuclei and cross-walls were stained by $4^{\prime}, 6-$ diamidino-2-phenylindole (DAPI, Sigma) and calcofluor (Polysciences), respectively. At least 400 apices were examined in each sample for actin fluorescence. The figures show results typical from at least three different labelling experiments.

\section{RESULTS AND DISCUSSION}

\section{Effect of CA on growth of $A$. nidulans}

The primary effect of cytochalasins is the inhibition of actin polymerization (Srinivasan et al., 1996) but these compounds also affect functions not yet known to be related to the actin cytoskeleton, such as glucose transport across cell membranes (Lin \& Spudich, 1974) and mitochondrial respiration (Manavanthu et al., 1980). In the present work, the effect of different concentrations of $\mathrm{CA}$ on the growth of $A$. nidulans mycelium in both solid (Fig. 1) and liquid media was studied. The concentration of the drug that inhibited growth by $30 \%$ was chosen for the experiments and its effect on the actin cytoskeleton was confirmed by IIF microscopical studies.

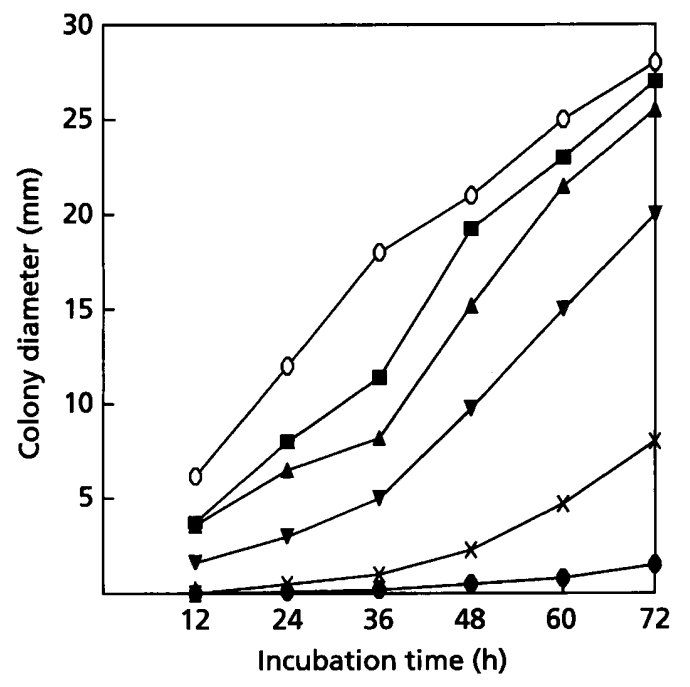

Fig. 1. Growth of $A$. nidulans in the absence or presence of $C A$ on solid medium. $O$, Control;,$C A$ at $10 \mu \mathrm{g} \mathrm{m}^{-1} ; A, C A$ at $20 \mu \mathrm{g} \mathrm{ml}^{-1} ; \nabla$, CA at $50 \mu \mathrm{g} \mathrm{ml}^{-1} ; \times, \mathrm{CA}$ at $80 \mu \mathrm{g} \mathrm{ml}^{-1} ; 0, \mathrm{CA}$ at $100 \mu \mathrm{g} \mathrm{ml}^{-1}$. SE were less than $10 \%$ of the mean. 

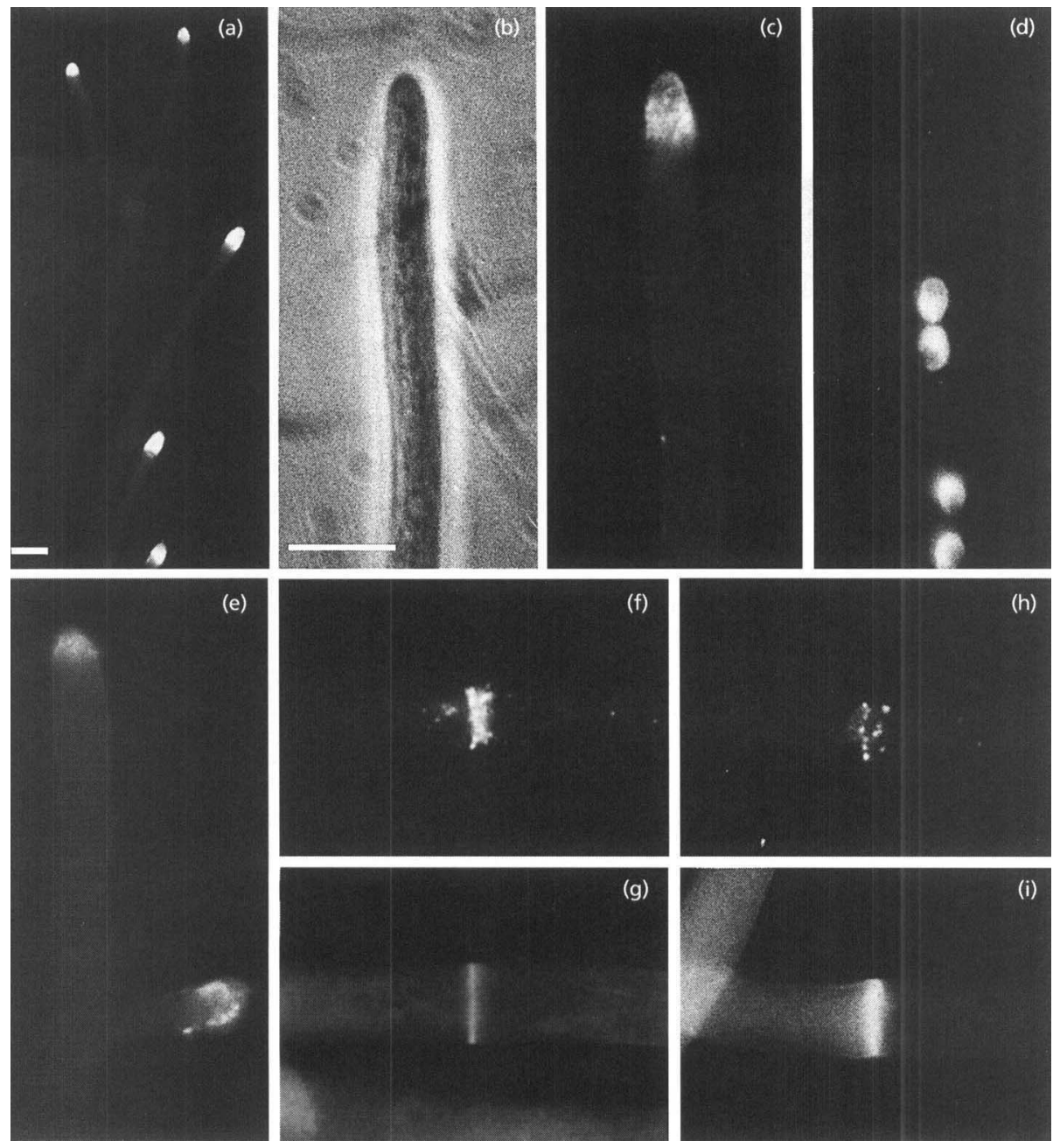

Fig. 2. Control hyphae of $A$. nidulans. (a) Immunofluorescence of actin at hyphal tips; (b-d) phase-contrast microscopy (b), IIF microscopy with antiactin antibody (c), and DAPI-staining (d) of the same hyphal tip; (e) actin localization in main hyphal tip and a branch tip; (f-i) IIF microscopy with antiactin antibody $(f, h)$ and calcofluor staining $(g, i)$ of two septa, at early $(f, g)$ and advanced $(h, i)$ stages of septum development. Bars, $5 \mu \mathrm{m}$.

In MYL plates, a sublethal dose of $20 \mu \mathrm{g} \mathrm{CA} \mathrm{m}^{-1}$ caused $30 \%$ growth inhibition and was chosen for IIF microscopical studies, for which the mycelium was grown on solid medium. In liquid medium, increasing amounts of CA progressively reduced growth, but higher doses of CA were required to obtain growth inhibition similar to that in solid medium (data not shown). In liquid medium, $80 \mu \mathrm{g} \mathrm{CA} \mathrm{ml}^{-1}$ was required to obtain $30 \%$ inhibition of growth and therefore this concentration was chosen for studies of secretion.

\section{Effect of CA on hyphal morphology and actin distribution}

IIF microscopical studies of control hyphae of $A$. nidulans visualized actin at sites of wall growth, at hyphal and branch apices (Fig. 2a-c, e), and at the sites of developing septa (Fig. 2f-i). Similar actin distribution has been detected previously in A. nidulans germ tubes
(Harris et al., 1994; McGoldrich et al., 1995), and also in the hyphae of other filamentous fungi and in yeast cells by using IIF techniques and/or fluorescently labelled phallotoxins (Hoch \& Staples, 1983; Adams \& Pringle, 1984; Marks \& Hyams, 1985; Runeberg et al., 1986; Tucker et al., 1986; Butt \& Heath, 1988; Salo et al., 1989; Raudaskoski et al., 1991; Roberson, 1992; Srinivasan et al., 1996).

Antiactin antibodies revealed strong actin fluorescence at the tip of $98 \%$ of the main hyphae and branches of $A$. nidulans (Fig. 2a). Most of the previous studies in yeast and filamentous fungi visualized actin as plaques or peripheral dots, whereas the present study also showed areas with more homogeneous actin fluorescence (Fig. $2 c$ ), which could be due to differences in the fixation methods used. The comparison of actin fluorescence and calcofluor staining of developing septa indicated that at initial stages of septum formation, actin formed a dense double band (Fig. 2f, g). During the development 

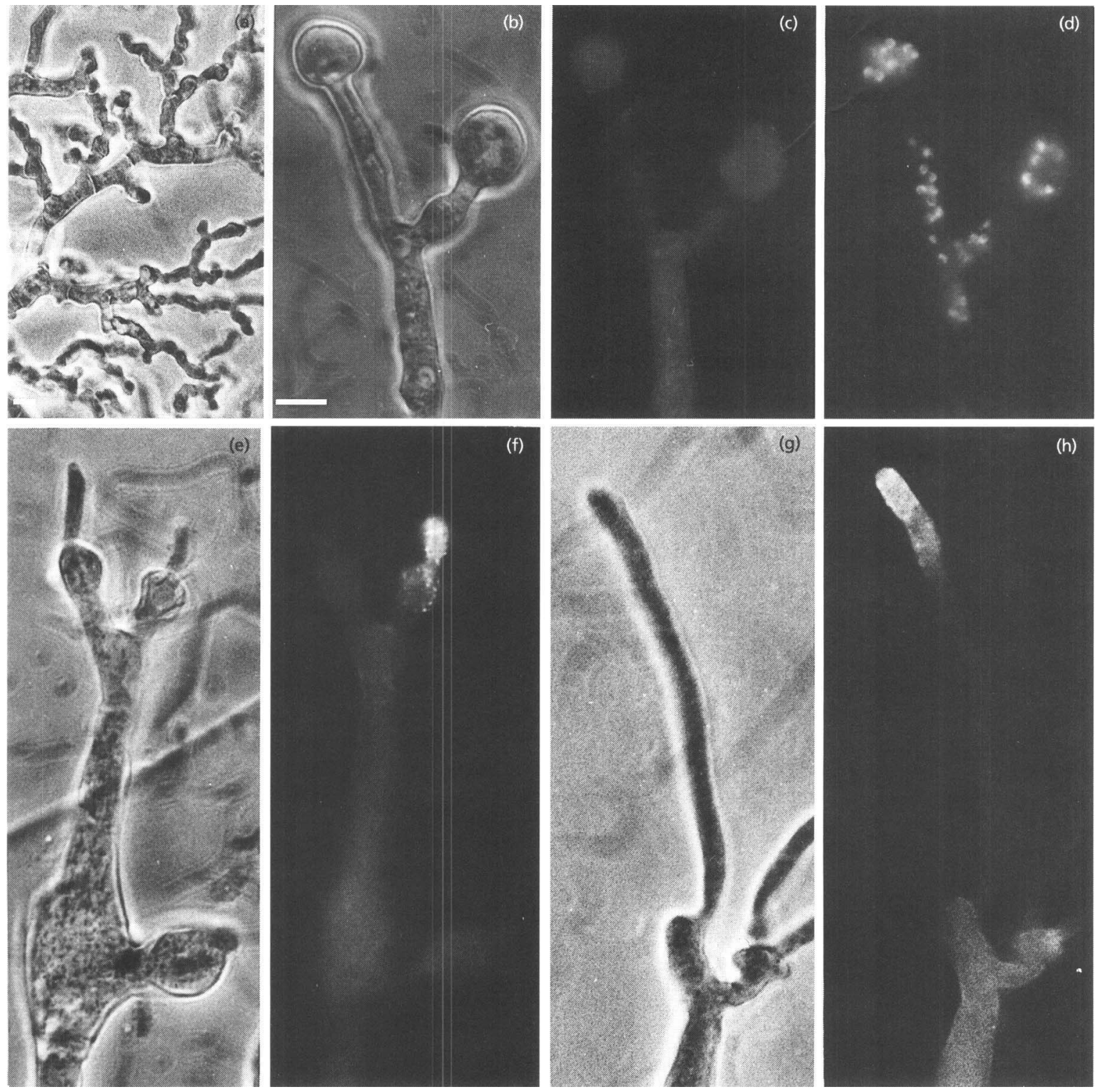

Fig. 3. Hyphae of $A$. nidulans treated with CA at $20 \mu \mathrm{g} \mathrm{ml}^{-1}$. (a) Colony edge after $4 \mathrm{~h}$ growth on CA medium; (b-d) phase-contrast microscopy (b), IIF microscopy with antiactin antibody (c) and DAPI staining of nuclei (d) in the same swollen hypha after $3 \mathrm{~h}$ CA treatment [note the lack of actin fluorescence from swollen part of the hypha (c), and nuclei accumulating in swollen tips (d)]; (e, f) phase-contrast microscopy (e) and IIF microscopy with antiactin antibody (f) of the same hyphae after $4 \mathrm{~h}$ CA treatment showing resumption of apical growth from a swollen tip; $(\mathrm{g}, \mathrm{h}$ ) phase contrast (g) and actin staining $(\mathrm{h})$ of hypha in a more advanced stage of apical growth on CA-containing medium. Bars, $5 \mu \mathrm{m}$.

of the septum, actin fluorescence decreased and only two rows of actin spots were seen associated with septa in more advanced stages of formation (Fig. $2 \mathrm{~h}, \mathrm{i}$ ). Fully developed septa were stained only with calcofluor and not with antiactin antibody (not shown).

When colonies of $A$. nidulans were grown overnight on control medium and then transferred to MYL plates containing $20 \mu \mathrm{g} \mathrm{CA} \mathrm{ml} \mathrm{m}^{-1}$, the form of the apices changed from cylindrical to spherical and the tip of apical cells became swollen (Fig. 3a-d). Swelling of the hyphal tip due to cytochalasin treatment has been reported in several filamentous fungi (Oliver, 1973; Allen et al., 1980; Grove \& Sweigard, 1980; Tucker et al., 1986; Srinivasan et al., 1996). In Saccharomyces cerevisiae, spherical expansion without budding was reported in mutants with defects in actin (Novick \& Botstein, 1985) and actin-related proteins (Johnston et al., 1991), which suggests that the morphological changes that were observed in the A. nidulans hyphae were likely to result from the action of CA on actin. This was further supported by the lack of actin fluorescence from swollen tips (Fig. 3c). Hyphae of A. nidulans were able to return for periods to a normal pattern of growth 
in the presence of CA. New normal-looking cylindrical hyphae formed from the spheres were observed in $80 \%$ of hyphae in $4 \mathrm{~h}$ samples (Fig. 3e-h) and staining with antiactin antibodies was detected in $23 \%$ of the apices with cylindrical growth pattern. Several of the tips showed a stronger actin fluorescence than the control hyphae (Fig. 3f, h). The irregular beady appearance of the hyphae grown for $4 \mathrm{~h}$ in the presence of CA (Fig. $3 a, e)$ suggested that the tips would swell again after a period of normal growth.

In the presence of CA, colony expansion appeared to accelerate with time (Fig. 1). This could be due to either the adaptation of $A$. nidulans to cytochalasin treatment or breakdown of the drug in the medium. Aspergillus niger has been reported to adapt to several antifungal agents for reasons not yet clarified (Park et al., 1994, 1996). In $A$. nidulans, the cyclic alterations in the immunolocalization of actin at the tip of $A$. nidulans hyphae grown in presence of CA correlated well with the normal and abnormal growth pattern of the hyphal tip (Fig. 3), and suggested that the actin cytoskeleton could reassemble and normal apical growth resume for short periods of time in the presence of CA. Whether this pattern of adaptation to CA is related to the different phases of the cell cycle in the hyphae and could be involved in the accelerated expansion of the colonies during prolonged incubation on CA-containing medium has to be clarified in the future.

CA is known to alter the distribution of actin during the germination of Candida albicans (Akashi et al., 1994) and Neurospora crassa (Barja et al., 1991). However, actin location in Uromyces phaseoli (Tucker et al., 1986) and Saprolegnia ferax (Jackson \& Heath, 1990) was not disturbed by treatment with cytochalasin E. Harris et al. (1994) observed that CA inhibited septum formation in germlings of A. nidulans. Careful examination of CAtreated hyphae with a beaded growth pattern failed to show formation of septa or actin fluorescence associated with septa (not shown). This suggests that the function of actin in the development of septa is more sensitive to CA than it is in the tip growth.

In the control hyphae of $A$. nidulans, the nuclei occurred at a certain distance from the hyphal tip apex (Fig. 2b, d) but in hyphae treated with CA, the distribution of nuclei was abnormal. The nuclei aggregated in the spherical tips (Fig. 3d). This suggested that actin may play a role in nuclear distribution in $A$. nidulans, although the movement of nuclei has been shown to require microtubule-associated molecular motors (Morris et al., 1995). In yeast, mutations in the ACT1 gene of Saccharomyces cerevisiae have demonstrable effects on nuclear migration (Palmer et al., 1992) and a fungal actin-related protein was shown to be involved in this process in N. crassa (Plamann et al., 1994; Robb et al., 1995). In both untreated and CA-treated cells, many synchronous nuclear divisions were observed by IIF microscopy with antitubulin antibody (not shown), which indicated that CA has little if any effect on mitosis.
Table 1. Total $\alpha$-galactosidase and $\beta$-galactosidase activities during growth of $A$. nidulans in lactose medium in the absence or presence of $C A$

Total activity is the sum of the activities determined in the three fractions derived from the cultures (insoluble mycelial fraction, soluble mycelial fraction and culture filtrate). Data are shown as mean $\pm \mathrm{sE}$.

\begin{tabular}{|c|c|c|c|}
\hline \multirow[t]{2}{*}{ Enzyme } & \multirow[t]{2}{*}{$\begin{array}{l}\text { Incubation } \\
\text { time (h) }\end{array}$} & \multicolumn{2}{|c|}{$\begin{array}{l}\text { Total activity }[\mathrm{mU}(\mathrm{mg} \\
\left.\text { freeze-dried mycelium })^{-1}\right]\end{array}$} \\
\hline & & Control & $\begin{array}{c}+\mathrm{CA} \\
\left(80 \mu \mathrm{g} \mathrm{ml}^{-1}\right)\end{array}$ \\
\hline \multirow[t]{5}{*}{$\alpha$-Galactosidase } & 20 & $1 \cdot 46 \pm 0 \cdot 11$ & $1.45 \pm 0.08$ \\
\hline & 25 & $2 \cdot 59 \pm 0.18$ & $1.92 \pm 0.05$ \\
\hline & 30 & $4 \cdot 20 \pm 0.28$ & $1.99 \pm 0 \cdot 15$ \\
\hline & 35 & $5 \cdot 70 \pm 0 \cdot 23$ & $2 \cdot 32 \pm 0 \cdot 17$ \\
\hline & 40 & $6 \cdot 26 \pm 0 \cdot 21$ & $3 \cdot 27 \pm 0 \cdot 11$ \\
\hline \multirow[t]{5}{*}{$\beta$-Galactosidase } & 20 & $0.95 \pm 0.01$ & $0.54 \pm 0.01$ \\
\hline & 25 & $0.76 \pm 0.02$ & $0.66 \pm 0.03$ \\
\hline & 30 & $1.22 \pm 0.08$ & $0.76 \pm 0.04$ \\
\hline & 35 & $1.23 \pm 0.04$ & $0.82 \pm 0.02$ \\
\hline & 40 & $1 \cdot 54 \pm 0 \cdot 11$ & $1.20 \pm 0.08$ \\
\hline
\end{tabular}

\section{Effect of CA on production and distribution of enzymes in A. nidulans}

Total $\alpha$-galactosidase and $\beta$-galactosidase activities started to increase significantly only after $8 \mathrm{~h}$ incubation of mycelia in media with lactose as a carbon source. When the fungus was incubated in the presence of CA $\left(80 \mu \mathrm{g} \mathrm{m}^{-1}\right)$, enzyme production started at the same time as in the control culture, but about a $30 \%$ reduction of the total activity of the enzymes was observed over $40 \mathrm{~h}$ for reasons not yet known (Table 1).

The distribution of the $\alpha$ - and $\beta$-galactosidase activities in the three fractions obtained from the fungal cultures during the incubation of $A$. nidulans mycelia, with or without $80 \mu \mathrm{g} \mathrm{CA} \mathrm{ml}^{-1}$, is shown in Fig. 4. The activities determined in the culture filtrates, soluble mycelial and cell wall fractions are expressed as the percentage of the total activity. During the exponential growth of $A$. nidulans mycelium, secreted $\alpha$-galactosidase activity was detected in the culture medium (Fig. 4a) and in the insoluble mycelial fraction (Fig. 4b), which agrees with previously reported results (Ríos et al., 1993). When the fungus was grown in the presence of CA, the enzyme activity in the culture filtrate and cell wall fraction was reduced (Fig. $4 \mathrm{a}, \mathrm{b}$ ) while $\alpha$-galactosidase activity in the soluble mycelial fraction was found to increase (Fig. 4c).

No $\beta$-galactosidase activity was detected in culture filtrates (Fig. 4d), which agrees with the previous work (Fiedurek \& Ilczuk, 1990) and shows that $\beta$-galactosidase activity is not released to the culture medium. However, recent studies (Díaz et al., 1996, Torralba et al., 1996) have located this enzyme external to the cell 

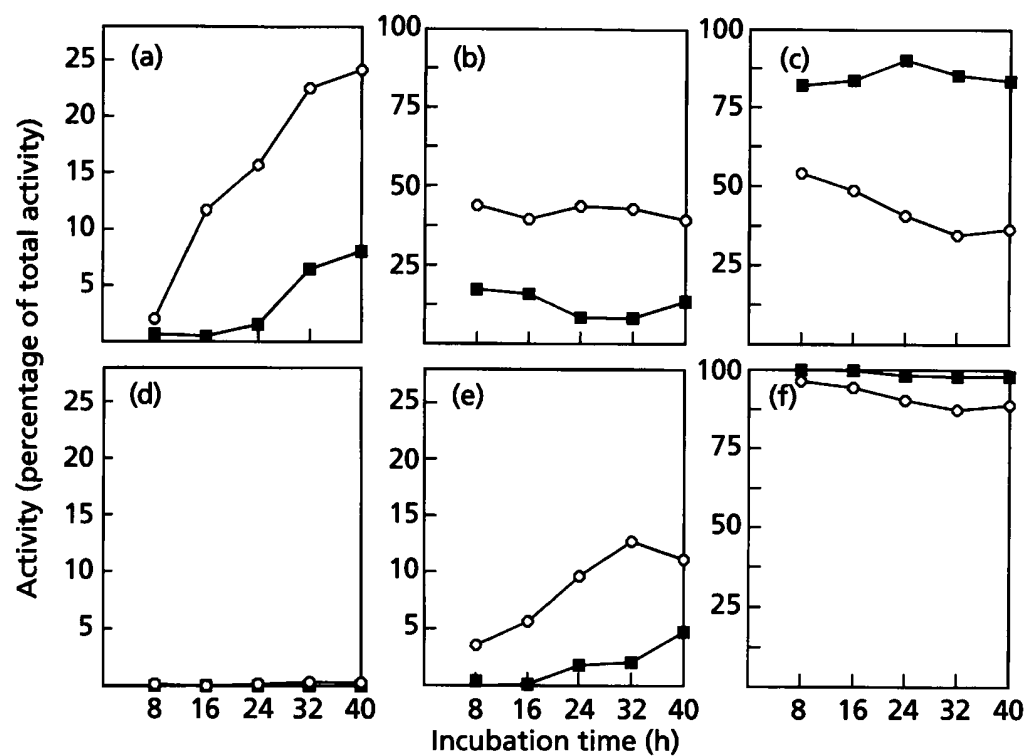

\begin{abstract}
Fig. 4. Distribution of $\alpha$-galactosidase $(a, b, c)$ and $\beta$-galactosidase $(d, e, f)$ activities in different fractions of $\boldsymbol{A}$. nidulans hyphae: culture filtrate $(a, d)$, mycelial insoluble fraction $(b, e)$ and mycelial soluble fraction (c, $f$ ) during incubation in lactose medium in the absence or presence of CA. $O$, Control; $\square, \mathrm{CA}$ at $80 \mathrm{\mu g} \mathrm{ml}^{-1}$. SE were less than $10 \%$ of the mean. Note that (a), (d) and (e) have different scales from (b), (c) and (f).
\end{abstract}

membrane, demonstrating that it has to be considered as a secreted enzyme, although not released to the supernatant. Our studies of enzyme distribution in A. nidulans mycelium showed that in control cultures around $10 \%$ of the total $\beta$-galactosidase activity was detected in the insoluble mycelial fraction. However, less than $5 \%$ of the total activity appeared bound to the cell wall in presence of CA (Fig. 4e). Besides, accumulation of the enzyme activity in the soluble mycelial fraction was observed in CA cultures (Fig. 4f). Our results suggest that the secretion of both $\alpha$-and $\beta$-galactosidase from $A$. nidulans mycelium was significantly decreased in the presence of CA. This agrees with a previous report which described inhibition of cellulase synthesis and secretion by CA in the oomycete Achyla (Thomas et al., 1974).

In protoplasts, total enzyme activities were not affected by the presence of $80 \mu \mathrm{g} \mathrm{CA} \mathrm{ml}{ }^{-1}$. After $16 \mathrm{~h}$ of enzyme induction, the total $\alpha$-galactosidase activity was $9.3 \mathrm{mU} \mathrm{ml}^{-1}$ in the control and $8.9 \mathrm{mU} \mathrm{ml}^{-1}$ in the presence of CA. $\beta$-Galactosidase activities in untreated and treated cells were 0.25 and $0.26 \mathrm{mU} \mathrm{ml}^{-1}$, respectively. About $60 \% \alpha$-galactosidase and $80 \% \quad \beta$-galactosidase activity was secreted to the medium by protoplasts (data not shown). The activities of $\alpha$ - and $\beta$ galactosidase in the extracellular medium were not due to lysis of protoplasts, since no activity of the intracellular enzyme malate dehydrogenase was detected in the culture medium. Therefore the $\alpha$ - and $\beta$-galactosidase activities measured in the culture medium must represent active secretion of proteins from the protoplasts. In contrast to the mycelium, no clear difference ocurred in enzyme secretion between control protoplasts and protoplasts treated with $80 \mu \mathrm{g} \mathrm{CA} \mathrm{ml}^{-1}$ (data not shown). In addition, higher concentrations of CA (100, 200 and $500 \mu \mathrm{g} \mathrm{ml}^{-1}$ ) did not modify either enzyme production or secretion by protoplasts. However, CA may have some effect on the actin cytoskeleton in protoplasts, since cell wall formation and tip growth were delayed in CA-treated protoplasts compared to the control, as observed by phase-contrast microscopy (not shown).

Cytochalasin-induced disruptions of the actin cytoskeleton, indicated by IIF microscopical studies, could result in the alterations of hyphal morphology and inhibition of enzyme secretion observed here. The disturbances in the actin cytoskeleton may block secretory vesicle transport to the apex. In another tipgrowing cell, the movement of comparable vesicles was inhibited by cytochalasins (Lancelle \& Hepler, 1988). However, one might not expect a similar transport of vesicles in secretion by protoplasts, which could help explain the unchanged level of secretion observed here in the presence of CA. These results would support the hypothesis that actin has a primary role in the movement of secretory vesicles in filamentous fungi. S. cerevisiae mutants with defects in the actin cytoskeleton showed accumulation of secretory vesicles (Novick \& Botstein, 1985; Johnston et al., 1991; Liu \& Bretscher, 1992) and inhibition of invertase secretion (Novick \& Botstein, 1985).

Our results support the hypothesis that actin has a primary role in the movement of secretory vesicles in fungi and that an actin-based system controls the polarity of hyphal growth and secretion in A. nidulans. This is also supported by the involvement of a novel myosin $\mathrm{I}$ in polarized growth and secretion in $A$. nidulans (McGoldrich et al., 1995). However it has been suggested that microtubules are also involved in these processes in filamentous fungi (Howard \& Aist, 1980; Raudaskoski et al., 1994; Rupes et al., 1995; Pedregosa et al., 1995) including A. nidulans (De Lucas et al., 1993; Jochová et al., 1993; Torralba et al., 1996). Therefore, further studies should be done to establish the definitive role and possible interrelations of microtubules, actin and myosin during fungal growth and protein secretion. 


\section{ACKNOWLEDGEMENTS}

S. Torralba was supported by a grant from the Community of Madrid (Spain). We thanks Ms M. Uuskallio for skilful technical assistance.

\section{REFERENCES}

Adams, A. \& Pringle, J. (1984). Localization of actin and tubulin in wild type and morphogenetic-mutant Saccharomyces cerevisiae. J Cell Biol 98, 934-945.

Akashi, T., Kanbe, T. \& Tanaka, K. (1994). The role of the cytoskeleton in the polarized growth of the germ tube in Candida albicans. Microbiology 140, 271-280.

Allen, E. D., Aiuto, R. \& Susman, A. S. (1980). Effects of cytochalasins on Neurospora crassa. I. Growth and ultrastructure. Protoplasma 102, 63-75.

Archer, D. B. \& Wood, D. A. (1994). Fungal exoenzymes. In The Growing Fungus, pp. 137-162. Edited by N. A. R. Gow \& G. M. Gadd. London: Chapman \& Hall.

Barja, F., Nguyen, B. \& Turian, G. (1991). Localization of actin and characterization of its isoforms in the hyphae of Neurospora crassa. FEMS Microbiol Lett 77, 19-24.

Bourett, T. M. \& Howard, R. J. (1991). Ultrastructural inmunolocalization of actin in a fungus. Protoplasma 163, 199-202.

Brightwell, R. \& Tappel, A. (1968). Lysosomal acid pyrophosphatase and acid phosphatase. Arch Biochem Biophys 124, 333-334.

Butt, T. M. \& Heath, I. B. (1988). The changing distribution of actin and nuclear behavior during the cell cycle of the mitepathogenic fungus Neozygites sp. Eur J Cell Biol 46, 499-505.

Chang, P. L. \& Trevithick, J. R. (1974). How important is secretion of exoenzymes through apical cell walls of fungi? Arch Microbiol 101, 281-293.

Clark, W. L. \& Lubs, H. A. (1917). The colorimetric determination of hydrogen ion concentration and its applications in Bacteriology. J Bacteriol 2, 1.

Czymmek, K. J., Bourettt, T. M. \& Howrad, R. J. (1995). Inmunolocalization of tubulin and actin in thick-sectioned fungal hyphae after freeze-substitution fixation and methacrilate de-embedment. J Microsc 181, 153-161.

De Lucas, J. R., Monistrol, I. F. \& Laborda, F. (1993). Effect of antimicrotubular drugs on the secretion process of extracellular proteins in Aspergillus nidulans. Mycol Res 97, 961-966.

Dlaz, M. S., Pedregosa, A. M., De Lucas, J.R., Torralba, S, Monistrol, I. F. \& Laborda, F. (1996). Purification and properties of $\beta$-galactosidase from Aspergillus nidulans. Microbiol SEM 12, 585-592.

Fantes, P. A. \& Roberts, C. F. (1973). $\beta$-Galactosidase activity and lactose utilization in Aspergillus nidulans. J Gen Microbiol 77, $471-486$.

Farkas, V. (1979). Biosynthesis of cell walls of fungi. Microbiol $\operatorname{Rev} 43,117-144$.

Fidel, S., Doonan, J. H. \& Morris, N. R. (1988). Aspergillus nidulans contains a single actin gene which has unique intron locations and encodes a $\gamma$-actin. Gene 70, 283-293.

Fiedurek, J. \& Ilczuk, Z. (1990). Screening of microorganisms for improvement of $\beta$-galactosidase production. Acta Microbiol Pol 39, 37-42.

Gooday, G. W. (1994). Cell walls. In The Growing Fungus, pp. 43-62. Edited by N. A. R. Gow \& G. M. Gadd. London: Chapman \& Hall.
Grove, S. N. \& Sweigard, J. A. (1980). Cytochalasin A inhibits spore germination and hyphal growth in Gilbertella persicaria. Exp Mycol 4, 239-250.

Harris, S. D., Morrell, J. L. \& Hamer, J. E. (1994). Identification and characterization of Aspergillus nidulans mutants defective in cytokinesis. Genetics 136, 517-532.

Heath, I. B. (1990). The roles of actin in tip growth of fungi. Int Rev Cytol 123, 95-127.

Heath, I. B. (1994). The cytoskeleton. In The Growing Fungus, pp. 100-134. Edited by N. A. R. Gow \& G. M. Gadd. London: Chapman \& Hall.

Hoch, H. C. \& Staples, R. C. (1983). Ultrastructural organization of the non differentiated uredospore germling of Uromyces phaseoli var. typica. Mycologia 75, 785-824.

Howard, D. R. J. \& Aist, J. E. (1980). Cytoplasmic microtubules and fungal morphogenesis: ultrastructural effects of methyl benzimidazole-2-yl-carbamate determinated by freeze-substitution of hyphal tip cells. J Cell Biol 87, 55-64.

Jackson, S. L. \& Heath, I. B. (1990). Evidence that actin reinforces the extensible hyphal apex of the oomycete Saprolegnia ferax. Protoplasma 157, 144-153.

Jochová, J., Rupes, I. \& Peberdy, J. F. (1993). Effect of the microtubule inhibitor benomyl on protein secretion in Aspergillus nidulans. Mycol Res 97, 22-27.

Johnston, G. C., Prendergast, J. A. \& Singer, R. A. (1991). The Saccharomyces cerevisiae MYO2 gene encodes an essential myosin for vectorial transport of vesicles. J Cell Biol 113, 539-551.

Lancelle, S. A. \& Hepler, P. K. (1988). Cytochalasin-induced ultrastructural alterations in Nicotiana pollen tubes. Protoplasma (suppl.) 2, 65-75.

Lin, S. \& Spudich, J. A. (1974). Biochemical studies on the mode of action of Cytochalasin B. J Biol Chem 249, 5778-5783.

Liu, H. \& Bretscher, A. (1992). Characterization of TPM1 disrupted yeast cells indicates an involvement of tropomyosin in directed vesicular transport. J Cell Biol 118, 285-299.

Lowe, D. A. (1992). Fungal enzymes. In Handbook of Applied Microbiology, vol. 4, pp. 681-706. Edited by D. K. Arora, R. P. Elander \& K. G. Mukerji. New York: Marcel Dekker.

McGoldrich, C. A., Gwuer, C. \& May, G. S. (1995). myoA of Aspergillus nidulans encodes an essential myosin I required for secretion and polarized growth. J Cell Biol 128, 577-587.

Manavanthu, E. K., Thomas, D. \& Des, S. (1980). Selectivity of cytochalasin A as a respiratory inhibitor. FEMS Microbiol Lett 7, 199-202.

Marks, J. \& Hyams, J. S. (1985). Localization of F-actin through the cell division cycle of Saccharomyces pombe. Eur J Cell Biol 39, 27-32.

Morris, R. N., Xiang, X. \& Beckwith, S. M. (1995). Nuclear migration advances in fungi. Trends Cell Biol 5, 278-282.

Monistrol, I. F., Pérez-Leblic, M. I. \& Laborda, F. (1988). Effect of sublethal dose of benomyl on extracellular enzyme production by Cladosporium cucumerinum. Trans Br Mycol Soc 90, 193-197.

Novick, P. \& Botstein, D. (1985). Phenotypic analysis of temperature-sensitive yeast actin mutants. Cell 40, 405-416.

Novick, P. \& Sheckman, R. (1983). Export of major cell surface proteins is blocked in yeast secretory mutants. $J$ Cell Biol 96, 541-547.

Oliver, P. T. P. (1973). Influence of cytochalasin B on hyphal morphogenesis of Aspergillus nidulans. Protoplasma 76, 279-281.

Palmer, R. E., Sullivan, D. S., Huffaker, T. \& Koshland, D. (1992). 
Role of astral microtubules and actin in spindle orientation and migration in the budding yeast Saccharomyces cerevisiae. J Cell Biol 119, 583-593.

Park, J. C., Yasuyuki, N., Homma, T., Sato, R., Matsuoka, H., Ohno, H., Takatori, K. \& Kurata, H. (1994). Adaptation of A. niger to several antifungal agents. Microbiology 140, 2409-2414.

Park, J. C., Matsuoka, H., Takatori, K. \& Kurata, H. (1996). Adaptation of $A$. niger to acidic conditions and its relationship to salt stress and miconazole. Mycol Res 100, 869-874.

Peberdy, J. F. (1994). Protein secretion in filamentous fungi trying to understand a highly productive black box. Trends Biotechnol 12, 50-57.

Pedregosa, A. M., Ríos, S., Monistrol, I. F. \& Laborda, F. (1995). Effect of the microtubule inhibitor methyl benzimidazol-2-yl carbamate $(\mathrm{MBC})$ on protein secretion and microtubule distribution in Cladosporium cucumerinum. Mycol Res 99, 43-48.

Peterbauer, C. K., Heidenreich, E., Baker, R. T. \& Kubicek, C. P. (1992). Effect of benomyl and benomyl resistance on cellulase formation by Trichoderma reesei and Trichoderma harzianum. Can J Microbiol 38, 1292-1297.

Plamann, M., Minke, P. E., Tinsley, J. H. \& Bruno, K. S. (1994). Cytoplasmic dynein and actin-related protein Arp1 are required for normal nuclear distribution in filamentous fungi. J Cell Biol 127, 139-149.

Pontecorvo, G., Roper, J. A., Hemmons, L. M., MacDonalk, K. D. \& Buffon, A. W. J. (1953). The genetics of A. nidulans. Adv Gen 5, 141-238.

Pryer, N. K., Wuestehube, L. J. \& Sheckman, R. (1992). Vesiclemediated protein sorting. Annu Rev Biochem 61, 471-516.

Punt, P. J., Veldhuisen, G. \& Van den Hondel, C. A. M. J. J. (1994). Protein targeting and secretion in filamentous fungi. Antonie Leeuwenhoek 65, 211-216.

Raudaskoski, M., Rupes, I. \& Timonen, S. (1991). Inmunofluorescence microscopy of the cytoskeleton in filamentous fungi after quick-freezing and low-temperature fixation. Exp Mycol 15, 167-173.

Raudaskoski, M., Mao, W. \& Yli-Mattila, T. (1994). Microtubule cytoskeleton in hyphal growth. Response to nocodazole in a sensitive and a tolerant strain of the homobasidiomycete Schizophillum commune. Eur J Cell Biol 64, 131-141.

Rlos, S., Pedregosa, A. M., Monistrol, I. F. \& Laborda, F. (1993). Purification and molecular properties of an $\alpha$-galactosidase synthesized and secreted by Aspergillus nidulans. FEMS Microbiol Lett 112, 35-42.

Robb, M. J., Wilson, M. A. \& Vierula, P. J. (1995). A fungal actinrelated protein involved in nuclear migration. Mol Gen Genet 247, 583-590.
Roberson, R. W. (1992). The actin cytoskeleton in hyphal cells of Sclerotium rolfsii. Mycologia 84, 41-51.

Runeberg, P., Raudaskoski, M. \& Virtanen, I. (1986). Cytoskeletal elements in the hyphae of the homobasidiomycete Schizophyllum commune visualized with indirect inmunofluorescece and NBDphallacidin. Eur J Cell Biol 41, 25-32.

Rupes, I., Mao, W., Astrom, H. \& Raudaskoski, M. (1995). Effects of nocodazole and brefeldin A on microtubule cytoskeleton and membrane organization in the homobasidiomycete Schizophyllum commune. Protoplasma 185, 212-221.

Salo, V., Niini, S. S., Virtanen, M. \& Raudaskoski, M. (1989). Comparative inmunocytochemistry of the cytoskeleton in filamentous fungi with dikaryotic and multinucleate hyphae. $J$ Cell Sci 94, 11-24.

Sheckman, R. \& Novick, P. (1982). The secretory process and yeast cell surface assembly. In The Molecular Biology of the Yeast Saccharomyces. Metabolism and Gene Expression, pp. 361-398. Edited by J. N. Strathern, E. W. Jones \& J. R. Broach. Cold Spring Harbor, NY: Cold Spring Harbor Laboratory.

Srinivasan, S., Vargas, M. M. \& Roberson, R. W. (1996). Functional, organizational, and biochemical analysis of actin in hyphal tip cells of Allomyces macrogynus. Mycologia 88, 57-70.

Tanner, W. \& Lehle, L. (1987). Protein glycosylation in yeast. Biochim Biophys Acta 906, 81-99.

Thomas, D., Des, S., Lutzac, M. \& Manavathu, E. K. (1974). Cytochalasin selectively inhibits synthesis of a secretory protein, cellulase, in Achlya. Nature 249, 140-142.

Torralba, S., Pedregosa, A. M., De Lucas, J. R., Dlaz, M. S., Monistrol, I. F. \& Laborda, F. (1996). Effect of the microtubule inhibitor methyl benzimidazol-2-yl carbamate (MBC) on production and secretion of enzymes in Aspergillus nidulans. Mycol Res 100, 1375-1382.

Tucker, B. E., Hoch, H. C. \& Staples, R. C. (1986). The involvement of F-actin in Uromyces cell differentiation: the effects of cytochalasin E and phalloidin. Protoplasma 176, 43-52.

Vainstein, M. H. \& Peberdy, J. F. (1991). Regulation of invertase in Aspergillus nidulans: effect of different carbon sources. J Gen Microbiol 137, 315-321.

Wessels, J. G. H. (1993). Wall growth, protein secretion and morphogenesis in fungi. New Phytol 123, 397-413.

Wösten, H. A. B., Moukha, S. M., Sietsma, J. H. \& Wessels, J. G. H. (1991). Localization of growth and secretion of proteins in Aspergillus niger. J Gen Microbiol 137, 2017-2023.

Received 30 June 1997; revised 5 September 1997; accepted 15 September 1997. 